\title{
THE ASSOCIATION BETWEEN SEVERITY OF MALOCCLUSSION WITH CARIES AMONG ADOLESCENTS STUDENTS OF SMKN 3 PARIAMAN Kartika wulandari ${ }^{1}$ dan Susi $^{2}$ \\ ${ }^{1}$ Faculty of Dentistry Andalas University \\ ${ }^{2}$ Departemen of Dental Public Health Faculty of Dentistry Andalas University
}

\begin{abstract}
Malocclussion is one of the most common case in oral health and taking of third position after dental caries and periodontal disease. Malocclusion is a deviation form from normal occlussion. Malocclussion may caused problems in oral function, psychosocial problems and oral health problem, one of them is caries. Many of malocclusion character associated with severity of caries. The aim of this study was to know the association between severity of malocclussion with caries among adolescents students in SMKN 3 Pariaman. This study use observasional analytics with cross sectional approach. Sample were adolescents (16-19 years old) in SMKN 3 Pariaman.The sample were 75 students consisting of 15 students in each of grade complexity of malocclusion. The severity of malocclusion were identification based ICON (Index of Complexity, Outcome and Need) and caries was assess use DMF-T Index. The data were analyzed by Kruskal Walis test and Mann-Whitney test. Mean DMF-T students of SMKN 3 Pariaman was 3,00 $\pm 1,716$ (medium category). DMF-T indeks of malocclusion Easy was 1,466 $\pm 1,407$ (low category), Mild is 1,933 $\pm 1,222$ (low category), Moderate was 3,133 $\pm 1,125$ (medium category), Difficult was 4,066 \pm 1 , (medium category), and Very Difficult was 4,400 $\pm 1,298$ (medium category). Mean of DMF-T indeks increased with increasing ICON of malocclusion. Statistical test result obtained by the $p$-value $(p<0,05)$. There were association between severity of malocclussion with caries among adolescents students in SMKN 3 Pariaman.
\end{abstract}

Key words : malocclussion, ICON, caries, DMF-T index

Affiliasi penulis: ${ }^{2}$ Departemen of Dental Public Health Faculty of Dentistry Andalas University Korespondensi: Susi

email: susiabidin@gmail.com

\section{PENDAHULUAN}

Susunan gigi yang tidak teratur dan keadaan oklusi yang tidak sesuai dengan keadaan normal tentunya merupakan suatu bentuk masalah kesehatan gigi dan mulut. ${ }^{1-}$

${ }^{3}$ Data Riset Kesehatan Dasar (Riskesdas) tahun 2013 menunjukkan prevalensi nasional untuk masalah gigi dan mulut di Indonesia adalah sebesar 25,9\%, prevalensi ini naik dibanding tahun 2007 lalu yaitu sebesar 23,4\%. Prevalensi masalah gigi dan mulut Provinsi Sumatera Barat sebesar 22,2\%.,
Salah satu masalah gigi dan mulut yang sering terjadi adalah maloklusi. Maloklusi adalah penyimpangan oklusi dari keadaan oklusi normal. ${ }^{1,2,3}$ Maloklusi dapat berupa ketidakteraturan gigi geligi atau yang keluar dari posisi ideal, serta hubungan yang tidak tepat antar rahang dilihat dari berbagai bidang. ${ }^{3,6,7,8}$

Maloklusi menempati urutan ketiga dalam masalah kesehatan gigi dan mulut setelah karies dan penyakit periodontal. ${ }^{2,3,6}$ Penelitian yang dilakukan pada gigi permanen di Pakistan tahun 2015 menunjukkan prevalensi maloklusi pada remaja sebesar $75,6 \% .^{9}$ Beberapa peneliti di bidang ortodonti lainnya mengatakan bahwa prevalensi maloklusi pada remaja 
Indonesia menunjukkan angka yang sangat tinggi. Prevalensi maloklusi remaja Indonesia mulai tahun 1983 sebesar 90\% dan pada tahun 2006 sebesar $89 \%{ }^{2}$

Maloklusi biasanya dibedakan berdasarkan klasifikasi. Klasifikasi maloklusi yang paling terkenal adalah klasifikasi menurut Angle. Klasifikasi Angle berguna untuk memudahkan seseorang mengingat gambaran maloklusi. ${ }^{6,10}$ Namun, klasifikasi Angle tidak menunjukkan tingkat keparahan maloklusi meskipun terletak pada satu kelas yang sama, sehingga diperlukan adanya suatu ukuran atau acuan dalam penilaian maloklusi. ${ }^{10}$ Penilaian maloklusi dapat dilakukan dengan menggunakan indeks maloklusi. Indeks maloklusi yang dapat digunakan, yaitu Handicapping Labio-lingual Deviation Indek (HLD), Swedish Medical Board Index (SMBI), Dental Aesthetic Index (DAI), Index of Complexity, Outcome and Need (ICON ), Peer Assesment Rating Index (PAR), Index of Orthodontic Complexity (IOTC), Index of Orthodontic Treatment Need (IOTN), dan sebagainya. ${ }^{10,11}$

ICON (Index of Complexity, Outcome and Need) merupakan indeks maloklusi yang digunakan untuk menilai tingkat keparahan maloklusi, tingkat kebutuhan perawatan, dan untuk menilai tingkat keberhasilan perawatan. Komponen yang di ukur dalam ICON adalah komponen estetik, diastema rahang atas dan crowding rahang atas, crossbite, relasi vertikal anterior (openbite dan overbite), dan relasi antero-posterior segmen bukal. Skor akhir ICON didapatkan dengan cara menghitung setiap komponen dan mengalikan dengan bobot masing-masing kemudian hasilnya dijumlahkan. ${ }^{10-14}$

Komponen estetik ICON diadaptasi dari IOTN (Index of Orthodontic Treatment Need), sehingga keparahan maloklusi juga dihitung dengan melihat komponen estetik gigi anterior. Dilihat dari cara perhitungannya, ICON lebih mudah digunakan karena menggunakan skor tunggal yang menggambarkan tingkat keparahan maloklusi dan kebutuhan perawatan. $^{11,12,13,14,15}$ Selain itu ICON juga lebih akurat dalam menentukan kebutuhan perawatan dibandingkan dengan indeks lainnya. ${ }^{16}$

Akibat yang dapat ditimbulkan dari berbagai keadaan maloklusi yaitu gangguan fungsi mulut, peningkatan kemungkinan trauma dan penyakit periodontal yang mempengaruhi kesehatan rongga mulut, serta masalah psikologis yang berhubungan dengan estetik dan kualitas hidup. ${ }^{3,6,9,17} \quad$ Karakteristik maloklusi seperti posisi gigi yang abnormal, anterior openbite, kelainan hubungan vertikal dan horizontal rahang 
atas dan bawah, pergeseran gigi, dan kelainan oklusi gigi posterior dapat menyebabkan gigi kerusakan jaringan periodontal, sehingga dapat menyebabkan karies gigi pada daerah servikal gigi. ${ }^{2,3}$ Posisi abnormal gigi atau gigi yang tidak teratur akan sulit dibersihkan dengan menyikat gigi dan memudahkan retensi plak, kemudian mempengaruhi oral hygiene sehingga memicu peningkatan terjadinya karies. ${ }^{2}$

Karies merupakan salah satu penyakit yang paling umum terjadi pada negara industri dan negara berkembang, dalam beberapa tahun terakhir telah terjadi perluasan peningkatan terhadap karies. ${ }^{18}$ Riset Kesehatan Dasar (Riskesdas) tahun 2013 menunjukkan bahwa prevalensi karies di Indonesia adalah 43,4\% dan prevalensi pengalaman karies sebesar $67,2 \%{ }^{4}$ Untuk menggambarkan tingkat keparahan kerusakan gigi permanen biasanya dilakukan penilalian dengan menggunakan indeks Decay Missing Filling-Tooth atau DMF-T. Data Riset Kesehatan Dasar (Riskesdas) tahun 2013 menunjukkan angka DMF-T nasional Indonesia sebesar 4,6. Angka ini menurun dari tahun 2007 lalu yaitu sebesar 4,85. Angka DMF-T Sumatera Barat adalah 4,7. Karies terus meningkat sesuai dengan bertambahnya umur, ini terlihat dari indeks
DMF-T pada berbagai kelompok umur. $4,5,20$

Karies gigi adalah penyakit yang mengenai jaringan keras gigi seperti email, dentin dan sementum yang disebabkan oleh berbagai faktor seperti host, agen, diet dan waktu. $^{19,20,21}$ Faktor waktu memegang peranan cukup penting dalam terjadinya karies, suatu karies dapat berkembang menjadi suatu kavitas dalam waktu yang bervariasi yaitu sekitar 6-48 bulan, tergantung interaksinya dengan faktorfaktor lain. Selain itu juga terdapat faktor yang mempunyai hubungan sebab akibat dengan terjadinya karies atau disebut juga faktor resiko. Faktor resiko terjadinya karies yaitu, pengalaman karies, penggunaan fluor, oral higiene, jumlah bakteri, saliva, dan pola makan. ${ }^{19,21}$

Shashank dkk (2014) juga melakukan penelitian mengenai hubungannya karies gigi permanen dengan tingkat keparahan maloklusi menggunakan indeks DAI (Dental Aestetic Index). DMF-T dan komponen D-T secara signifikan meningkat sesuai dengan peningkatan keparahan maloklusi berdasarkan DAI. Pada penelitian ini ditemukan adanya hubungan antara kejadian karies dengan tingkat keparahan maloklusi. $^{22}$

Carlos dkk (2015) menyatakan bahwa prevalensi dan keparahan karies gigi lebih besar terjadi pada remaja dengan tingkat 
maloklusi berat. Remaja dengan maloklusi berat atau handicaping mempunyai $31 \%$ kemungkinan lebih besar untuk menderita karies. Berbagai karakter ortodontik yang berkaitan dengan kejadian dan keparahan karies adalah adanya ketidakteraturan pada maksila $\geq 3 \mathrm{~mm}$ dan hubungan molar yang abnormal. $^{23}$

Maloklusi dan karies merupakan masalah kesehatan gigi dan mulut yang paling sering terjadi, baik pada remaja ataupun kelompok umur lainnya. ${ }^{1,2}$ Remaja merupakan masa transisi dari anak-anak ke dewasa yang ditandai oleh adanya perubahan fisik, emosi, dan psikis. Rentang usia remaja menurut WHO adalah 12-24 tahun, sedangkan menurut Depkes RI dan $\mathrm{BKKBN}$ rentang umur remaja Indonesia adalah 10-19 tahun dan belum menikah. Masa remaja terdiri dari tiga tahap, yaitu masa remaja awal, masa remaja tengah, dan masa remaja akhir. ${ }^{24}$ Penelitian akan dilakukan pada siswa SMK N 3 Pariaman yang berada pada rentang usia remaja akhir yaitu usia16-19 tahun, karena pada masa ini semua gigi permanen telah tumbuh secara sempurna, kecuali gigi molar 3 permanen. Selain itu, pada masa remaja akhir semua gigi permanen dirasa sudah cukup terpapar dengan keadaan rongga mulut yang memungkinkan terjadinya karies. ${ }^{19}$
Berdasarkan uraian diatas, peneliti tertarik untuk mengetahui tentang hubungan antara tingkat keparahan maloklusi berdasarkan ICON (Index of Complexity, Outcome and Need) dan karies pada remaja siswa SMKN 3.

\section{METODE PENELITIAN}

Jenis penelitian yang digunakan adalah rancangan penelitian observasional analitik dengan pendekatan cross sectional. Penelitian ini dilakukan di Laboratorium Biologi SMKN 3 Pariaman. Waktu penelitian dilaksanakan pada bulan Februari 2016. Sampel dalam penelitian ini adalah siswa SMKN 3 Pariaman yang memenuhi kriteria sebagai sampel. Metode pengambilan sampel dalam penelitian dengan menggunakan teknik purposive sampling. Setelah dilakukan perhitungan maka didapatkan jumlah sampel pada tiap tingkat keparahan maloklusi adalah 15. Karena terdapat 5 tingkat keparahan maloklusi maka total sampel adalah 75 orang. Kegiatan penelitian yaitu responden penelitian diminta membaca lembar informasi dan mengisi informed concent, pemeriksaan $D M F-T$, pencetakan rahang responden untuk mendaoatkan model studi, kemudian lakukan pengukuran tingkat keparahan maloklusi dari model studi yang tersedia. Pengukuran dilakukan dengan menggunakan Index of Complexity, 
Outcome and Need (ICON). Pengukuran dilakukan dengan menghitung 5 komponen, yaitu pengukuran yang pertama dilakukan adalah pengukuran komponen estetik ICON, dengan cara membandingkan model studi dengan 10 gambar yang ada, kemudian catat dan beri skor sesuai gambar yang paling mendekati.

Kemudian lakukan pengukuran pada komponen kedua, yaitu diastema dan berdesakan rahang atas. Caranya dengan melakukan pengukuran diskrepansi jumlah mesiodistal gigi geligi dengan lebar lengkung gigi, kemudian catat dan beri skor sesuai dengan tabel yang telah ada. Selanjutnya adalah pengukuran komponen ketiga, yaitu ada tidaknya crossbite, dengan cara mengoklusikan model studi rahang atas dan rahang bawah. Kemudian pengukuran relasi vertikal anterior yaitu pengukuran openbite dan overbite dengan cara mengoklusikan model studi

Tabel 1 Komponen $\operatorname{ICON}^{11,12,13,14}$

\begin{tabular}{|c|c|c|c|c|c|c|c|c|}
\hline \multirow[b]{2}{*}{ No } & \multirow[b]{2}{*}{ Komponen } & \multicolumn{6}{|c|}{ Skor } & \multirow{2}{*}{$\begin{array}{l}\text { Bo- } \\
\text { bot }\end{array}$} \\
\hline & & 0 & 1 & 2 & 3 & 4 & 5 & \\
\hline 1 & Estetik & & & Skor 1-10 & & & & 7 \\
\hline \multirow[t]{2}{*}{2} & $\begin{array}{l}\text { Berdesakan } \\
\text { Rahang atas }\end{array}$ & $<2 \mathrm{~mm}$ & $2,1-5 \mathrm{~mm}$ & $\begin{array}{c}5,1-9 \\
\mathrm{Mm}\end{array}$ & $\begin{array}{c}9,1-13 \\
\mathrm{~mm}\end{array}$ & $\begin{array}{c}13,1- \\
17 \\
\mathrm{~mm}\end{array}$ & $\begin{array}{l}>17 \\
\mathrm{~mm}\end{array}$ & 5 \\
\hline & $\begin{array}{l}\text { Distema } \\
\text { Rahang Atas }\end{array}$ & $<2 \mathrm{~mm}$ & $2,1-5 \mathrm{~mm}$ & $\begin{array}{l}5,1- \\
9 \mathrm{~mm}\end{array}$ & $>9 \mathrm{~mm}$ & & $\begin{array}{c}\text { Impaks } \\
\mathrm{i}\end{array}$ & 5 \\
\hline 3 & Croosbite & $\begin{array}{l}\text { Tidak ada } \\
\text { Crossbite }\end{array}$ & $\begin{array}{c}\text { Ada } \\
\text { Crossbite }\end{array}$ & & & & & 5 \\
\hline \multirow[t]{2}{*}{4} & $\begin{array}{l}\text { Openbite } \\
\text { Anterior }\end{array}$ & Normal & $<1 \mathrm{~mm}$ & $\begin{array}{l}1,1- \\
2 \mathrm{~mm}\end{array}$ & $\begin{array}{l}2,1- \\
4 \mathrm{~mm}\end{array}$ & $\begin{array}{l}>4 \\
\mathrm{~mm}\end{array}$ & & 4 \\
\hline & $\begin{array}{l}\text { Overbite } \\
\text { Anterior }\end{array}$ & $\begin{array}{l}\text { sampai } 1 / 3 \\
\text { gigi }\end{array}$ & $\begin{array}{c}\text { 1/3- } 2 / 3 \\
\text { bagian } \\
\text { insisiv } \\
\text { yang } \\
\text { tertutupi }\end{array}$ & $\begin{array}{c}\text { 2/3 sampai } \\
\text { seluruh } \\
\text { insisiv } \\
\text { bawah } \\
\text { tertutupi }\end{array}$ & $\begin{array}{c}\text { Seluruh } \\
\text { bagian } \\
\text { insisiv } \\
\text { bawah } \\
\text { tertutup } \\
\text { semua }\end{array}$ & & & 4 \\
\hline 5 & $\begin{array}{l}\text { Segmen bukal } \\
\text { Antero- } \\
\text { posterior }\end{array}$ & $\begin{array}{c}\text { Hanya relasi } \\
\text { cusp ke } \\
\text { embrasure, } \\
\text { Klas I,II dan } \\
\text { III }\end{array}$ & $\begin{array}{l}\text { Relasi cusp } \\
\text { yang lain } \\
\text { kecuali } \\
\text { cusp to } \\
\text { cusp }\end{array}$ & $\begin{array}{c}\text { Relasi cusp } \\
\text { to cusp }\end{array}$ & & & & 3 \\
\hline
\end{tabular}


Rahang atas dan rahang bawah. Komponen kelima yaitu relasi anteroposterior segmen bukal. Setelah semua komponen diukur dan didapatkan skor masing-masing komponen, selanjutnya masing-masing komponen dikalikan dengan bobot yang sesuai dengan tabel, kemudian hasil pekalian kelima komponen dijumlahkan. Dan didapatkanlah skor akhir ICON.

Tabel 2 Tingkat Keparahan Maloklusi. ${ }^{11,12,13}$

Tabel 2 Tingkat Keparahan Maloklusi. $11,12,13$

\begin{tabular}{|l|c|}
\hline \multicolumn{1}{|c|}{ Tingkat Keparahan Naloklusi } & Skor \\
\hline Easy & $<29$ \\
\hline Mild & $29-50$ \\
\hline Moderate & $51-63$ \\
\hline Difficult & $64-77$ \\
\hline Very Difficult & $>77$ \\
\hline
\end{tabular}

\section{HASIL PENELITIAN}

Analisis Univariat dilakukan untuk melihat distribusi DMF-T rata-rata siswa SMKN 3 Pariaman.

Tabel 3 Distribusi DMF-T

Tabel 3 Distribusi DMF-T
\begin{tabular}{|l|c|c|c|c|}
\hline Tingkat & & \multicolumn{3}{|c|}{ DMF-T } \\
\cline { 3 - 5 } $\begin{array}{l}\text { Keparahan } \\
\text { Maloklusi }\end{array}$ & (N) & Min & Max & Mean \pm SD \\
\hline Easy & 15 & 0,00 & 4,00 & $1,466 \pm 1,407$ \\
\hline Mild & 15 & 0,00 & 4,00 & $1,933 \pm 1,222$ \\
\hline Moderate & 15 & 1,00 & 5,00 & $3,133 \pm 1,125$ \\
\hline Difficult & 15 & 2,00 & 7,00 & $4,066 \pm 1,437$ \\
\hline Very Difficult & 15 & 2,00 & 7,00 & $4,400 \pm 1,298$ \\
\hline Total & 75 & 0 & 7 & $3,00 \pm 1,716$ \\
\hline
\end{tabular}

Berdasarkan tabel 5.3 dapat dilihat bahwa indeks DMF-T rata-rata siswa SMKN 3 Pariaman adalah 3,00 $\pm 1,716$. Nilai DMF-T minimum pada siswa SMKN 3 Pariaman adalah 0 dan untuk nilai maksimum adalah 7. Analisis Bivariat dilakukan untukmelihat Hubungan Indeks DMF-T dengan Tingkat Keparahan Maloklusi. Analisis bivariat yang digunakan pada penelitian ini adalah Kruskal Walis dengan nilai kemaknaan $(\mathrm{p}<0,05)$ karena distribusi data tidak normal.

Tabel 4 Distribusi DMF-T Masing-Masing Tingkat Keparahan Maloklusi

Tabel 4 Distribusi DMF-T Masing-Masing Tingkat Keparahan Maloklusi

\begin{tabular}{|l|c|c|c|}
\hline Tingkat Keparahan & & DMIF-T & \multirow{2}{*}{ p-value } \\
\cline { 2 - 3 } Maloklusi & (I) & MeantSD & \\
\hline Easy & 15 & $1,466 \pm 1,407$ & \\
\hline Mild & 15 & $1,933 \pm 1,222$ & \\
\hline Moderate & 15 & $3,133 \pm 1,125$ & 0 \\
\hline Difficult & 15 & 4,000 \\
\hline Verv Difficult & 15 & $4,400 \pm 1,1,437$ & \\
\hline
\end{tabular}

Berdasarkan tabel 5.5 dapat dilihat bahwa indeks DMF-T rata-rata paling rendah terdapat pada tingkat keparahan maloklusi Easy, yaitu 1,466 $\pm 1,407$. Dan bahwa indeks DMF-T rata-rata paling tinggi terdapat pada tingkat keparahan maloklusi

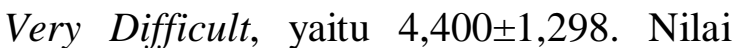
$\mathrm{p}<0,05$ yang berarti bahwa paling tidak terdapat perbedaan indeks DMF-T yang bermakna pada beberapa tingkat keparahan maloklusi.

Untuk melihat hubungan antara Tingkat Keparahan Maloklusi dengan Indeks DMF-T digunakan uji MannWhitney dengan nilai kemaknaan $(\mathrm{p}<0,05)$. 
Tabel 5 Hubungan antara tingkat keparahan maloklusi dengan indeks DMF$\mathrm{T}$

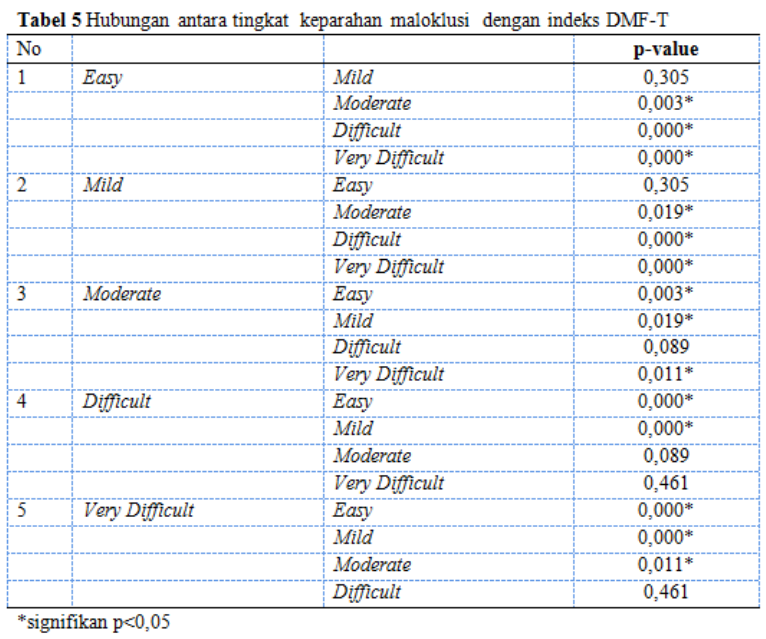

Berdasarkan tabel 5.6 dapat dilihat bahwa hampir semua tingkat keparahan maloklusi menunjukkan perbedaan indeks DMF-T yang signifikan $(\mathrm{p}<0,05)$, namun pada tingkat keparahan maloklusi EasyMild, Moderate-Difficult, dan DifficultVery Difficult tidak menunjukkan perbedaan indeks DMF-T yang signifikan $(\mathrm{p}>0,05)$

\section{PEMBAHASAN}

Indeks DMF-T rata-rata siswa SMKN 3 Pariaman adalah 3,00 $\pm 1,716$, dimana rata-rata terdapat 3 buah gigi yang rusak pada setiap remaja. Data Riset Kesehatan Dasar (Riskesdas) tahun 2013 menunjukkan angka DMF-T nasional Indonesia pada rentang usia 18 tahun (remaja akhir) adalah 1,6. ${ }^{5}$ Indeks DMF-T siswa SMKN 3 Pariaman menurut WHO termasuk kategori sedang, dari hasil penelitian terlihat bahwa DMF-T siswa
SMKN 3 Pariaman lebih buruk dibanding DMF-T nasional Indonesia yang termasuk kategori rendah pada rentang usia yang relatif sama.

Karies gigi adalah penyakit yang mengenai jaringan keras gigi seperti email, dentin dan sementum yang disebabkan oleh berbagai faktor seperti host, agen, diet dan waktu. $^{19,20,21}$ Karies dinyatakan sebagai penyakit multifaktorial yaitu adanya beberapa faktor yang menjadi penyebab terbentuknya karies. ${ }^{19,32}$ Faktor lain yang berperanan dalam terjadinya karies, yaitu pengalaman karies, penggunaan fluor, oral higiene, jumlah bakteri, saliva, pola makan/gaya hidup dan diet, umur, jenis kelamin, dam sosial ekonomi ${ }^{19,21}$

Pada penelitian ini yang akan dilihat adalah hubungan tingkat keparahan maloklusi dan karies yang akan dilihat menggunakan indeks DMF-T. Pada keadaan maloklusi faktor yang berkaitan dengan terjadinya karies adalah adanya berbagai karakter maloklusi yang nantinya berhubungan dengan penumpukan plak dan mempengaruhi oral hygene. Plak gigi memegang peranan penting dalam menyebabkan karies. Plak adalah lapisan lunak yang terdiri atas kumpulan mikroorganisme yang berkembang biak di atas matriks yang terbentuk dan melekat erat pada permukaan gigi yang tidak dibersihkan. Insiden karies dapat dikurangi 
dengan menjaga oral higiene dengan melakukan penyingkiran plak secara mekanis dari permukaan gigi. ${ }^{19}$

Karakter maloklusi yang lain juga berhubungan dengan penurunan fungsi saliva, seperti openbite, peningkatan overjet, dan lain-lain. Selain mempunyai efek bufer, saliva juga berguna untuk membersihkan sisa-sisa makanan di dalam mulut. Pada individu yang berkurang fungsi salivanya, maka aktivitas karies akan meningkat secara signifikan. ${ }^{1}$

Berdasarkan uji yang sudah dilakukan, terdapat hubungan yang signifikan $\quad(\mathrm{p}<0,05)$ antara tingkat keparahan maloklusi dan indeks DMF-T pada remaja. Tabel 5.4 menunjukkan bahwa semakin tinggi tingkat keparahan maloklusi, maka semakin tinggi indeks DMF-T. Indeks DMF-T untuk tingkat keparahan maloklusi Easy adalah $1,466 \pm 1,407$, berdasarkan kategori WHO tergolong pada kategori rendah. Indeks DMF-T untuk tingkat keparahan maloklusi Mild adalah 1,933 $\pm 1,222$, berdasarkan kategori WHO tergolong pada kategori rendah. Indeks DMF-T untuk tingkat keparahan maloklusi Moderate adalah $3,133 \pm 1,125$, berdasarkan kategori WHO tergolong pada kategori sedang. Indeks DMF-T untuk tingkat keparahan maloklusi Difficult adalah 4,066 $\pm 1,437$, berdasarkan kategori WHO tergolong pada kategori sedang. Indeks DMF-T untuk tingkat keparahan maloklusi Very Difficult adalah 4,400 $\pm 1,298$, berdasarkan kategori WHO tergolong pada kategori sedang. Indeks DMF-T untuk tingkat keparahan maloklusi Easy adalah 1,466 $\pm 1,407$, berdasarkan kategori WHO tergolong pada kategori rendah.

Terdapat berbagai karakter ortodontik/maloklusi yang berkaitan dengan kejadian dan keparahan karies. ${ }^{22}$ Peningkatan overjet berhubungan dengan peningkatan kemungkinan trauma, serta oral hygene yang buruk yang meningkatkan resiko poket periodontal, gingivitis dan karies. ${ }^{11}$ Kasus anterior open bite juga dapat menyebabkan karies gigi. Remaja dengan peningkatan overjet dan anterior open bite cenderung bernafas lewat mulut dan menyebabkan penurunan aliran saliva. Keadaan mulut yang kering akibat penurunan aliran jumlah saliva memudahkan mikroorganisme kariogenik penyebab karies gigi berkembang biak. ${ }^{2}$

Ketidakteraturan pada maksila $\geq$ $3 \mathrm{~mm}$ dan hubungan molar yang abnormal juga berkaitan dengan kejadian dan keparahan karies. $^{22}$ Kondisi gigi-geligi yang berjejal atau terjadi perubahan titik kontak mengakibatkan makanan terselip disela-sela gigi akan sulit dibersihkan dengan menyikat gigi dan memudahkan retensi plak, kemudian mempengaruhi oral 
hygiene sehingga memicu peningkatan terjadinya karies. ${ }^{2}$ Hal ini sesuai dengan penelitian Cahyadi (1997), anak dengan skor OHI-S rendah akan lebih rendah karies. $^{37}$ Kelainan oklusi gigi posterior dapat menyebabkan gigi kerusakan jaringan periodontal, sehingga dapat menyebabkan karies gigi pada daerah servikal gigi. ${ }^{3,18}$

Maloklusi yang parah dapat menimbulkan kesulitan menggerakkan rahang (gangguan TMJ dan nyeri). ${ }^{29}$ Gangguan TMJ Gangguan sendi rahang dapat menyebabkan kelainan mengunyah pada satu sisi rahang yang memicu terjadinya karies gigi di sisi yang tidak melakukan pengunyahan. Gigi geligi pada sisi rahang yang tidak melakukan aktivitas pengunyahan makanan terjadi penurunan aliran jumlah saliva yang akan menyebabkan gigi-geligi rentan terjadi karies. ${ }^{2}$ Terdapat perbedaan indeks DMF-T pada tiap tingkatan keparahan maloklusi, dimana terjadi peningkatan indeks DMF-T pada peningkatan tingkat keparahan maloklusi (tabel 5.4). Hal ini sesuai dengan penelitian yang dilakukan Shashank dkk (2014) mengenai hubungannya karies gigi permanen dengan tingkat keparahan maloklusi menggunakan indeks DAI (Dental Aestetic Index). DMF-T dan komponen D-T secara signifikan meningkat sesuai dengan peningkatan keparahan maloklusi berdasarkan DAI ${ }^{21}$ Dalam penelitian lain yang dilakukan Adhani (2014) disampaikan bahwa terdapat perbedaaan indeks karies antara maloklusi berat dan maloklusi ringan pada remaja. $^{2}$

Indeks DMF-T pada tingkat keparahan maloklusi Easy dan Mild tergolong kategori rendah dan tingkat keparahan maloklusi Moderate, Difficult, Very Difficult tergolong kategori sedang. Hal ini sesuai dengan penelitian Carlos dkk (2015) yang menyatakan bahwa prevalensi dan keparahan karies gigi lebih besar terjadi pada remaja dengan tingkat maloklusi berat. Remaja dengan maloklusi berat atau handicaping mempunyai $31 \%$ kemungkinan lebih besar untuk menderita karies. $^{22}$

Untuk mengetahui hubungan tiap tingkat keparahan maloklusi digunakan uji Mann-Whitney. Berdasarkan uji MannWhitney (tabel 5.5) dapat dilihat bahwa tidak terdapat hubungan yang signifikan ( $>0,05)$ antara tingkat keparahan EasyMild, Moderate-Difficult dan Difficult-Very Difficult. Hal ini disebabkan karena jarak tingkat keparahan maloklusi yang berdekatan sehingga tidak terdapat perbedaaan yang terlalu mencolok. Meskipun tidak terdapat hubungan berdasarkan uji statistik namun dari tabel 
5.4 terlihat bahwa terdapat perbedaan indeks DMF-T.

\section{KESIMPULAN}

Berdasarkan penelitian yang dilakukan mengenai hubungan tingkat keparahan maloklusi dengan karies pada remaja siswa SMKN 3 Pariaman, maka diperoleh kesimpulan bahwa terdapat hubungan antara tingkat keparahan maloklusi dengan karies yang dilihat menggunakan indeks DMF-T pada remaja.

\section{KEPUSTAKAAN}

1. Laguhi VA., dkk. Gambaran Maloklusi dengan Menggunakan HMAR pada Pasien di Rumah Sakit Gigi dan Mulut Universitas Sam Ratulangi Manado. Jurnal e-GiGi. 2014;2(2)

2. Adhani R., dkk. Perbedaan Indeks Karies antara Maloklusi Ringan dan Berat pada Remaja di Ponpes Darul Hijrah Martapura. Dentino Jurnal Kedokteran Gigi. 2014; 2(1):1317

3. Shenoy RP., dkk. Malocclusion and Orthodontic Treatment Need among High School Students in Mangalore City India. IBIMA Publissing. JMED Research. 2014. http:/www.ibimapublissing.com/journals/JME D/jmed.html

4. Riset Kesehatan Dasar (Riskesdas) 2007. Laporan hasil riset kesehatan dasar nasional tahun 2007 Jakarta: Badan Litbangkes, Depkes RI, 2008; p. 130-147

5. Riset Kesehatan Dasar (Riskesdas) 2013. Laporan hasil riset kesehatan dasar nasional tahun 2013 Jakarta: Badan Litbangkes, Depkes RI, 2013; p. 110-119

6. Uzuner FD., dkk. Angle's Classification Versus Dental Aesthetic Index in Evaluation of Malocclusion among Turkish Orthodontic Patients. J Dent Apps. Austi Publishing Group.2015;2(3):168-173

7. Nalcaci R., dkk. The Relationship of Orthodontic Treatment Need with Periodontal Status, Dental Caries and Sociodemographic Factors. The Scientific World Journal. 2012; Article ID 498012. 6 pages

8. Damle D., dkk. A Study of Occurrence of Malocclusion in 12 and 15 Year Age Group of Children in Rural and Backward Areas of Haryana, India. Journal of Indian Society of
Pedodontics and Preventive Dentistry. 2014; 32(4)

Downloaded free from http://www.jisppd.com on Wednesday. October 14, 2015. IP: 223.255.231.150

9. Assad A., dkk. Prevalence of Malocclusion and its Relationship with Dental Caries in A Sample of Pakistini School Children. Pakistan Oral \& Dental Journal. 2015; 35(2)

10. Rahardjo P. Ortodonti Dasar. Surabaya. Airlangga University Press. 2009

11. Borzabadi A. dan Farahani. An Overview of Selected Orthodontic Treatment Need Indices, Principles in Contemporary Orthodontics, Dr. Silvano Naretto (Ed.). InTech. 2011; ISBN: 978-953-307-687-4

Available from: http://www.intechopen.com/books/principlesin-contemporarymorthodontics/an-overviewof-selectedorthodontictreatment-need-indices

12. Daniel C. dan Richmond S. The Developmental of The Index of Complexity, Outcome and Need (ICON). J Orthod. 2000;27:149-162

13. Rosalia S., dkk. Gambaran Tingkat Keparahan Maloklusi dan Kebutuhan Perawatan Menggunakan Index of Complexity, Outcome and Need (ICON) di RSGM-P FKG Unair. Orthodontic Dental Journal. 2011; 2 (1):26-32

14. Aikins EA., dkk. Orthodontic Treatment Need and Complexity among Nigerian Adolescents in Rivers State, Nigeria. Hindawi Publissing Corporation. International Journal of Dentistry. 2011; Article ID 813523, 6 pages

15. Urtane I., dkk. Severity of Malocclusion and Need for Orthodontic Treatment in Correspondence wth The Age. Stomatologija. Baltic Dental and Maxillofacial Journal. 2006; $8(2)$

16. Costa RN., dkk. Validity of Two Occlusal Indeces for Determining Orthodontic Treatment Needs of Patients Treated in a Public Universityin Belo Horizonte, Minas Gerais State, Brazil. Cad Saude Publica. 2011;27(3):581-590

17. Profit WR., dkk. Contemporary Orthodontics, 4th ed. St Louis CV Mosby Co. 2007:3-22

18. Felton A., dkk. Basic Guide to Oral Health Education and Promotion, 2th ed. New Delhi: Wiley-Blackwell. 2014;73-83

19. Pintauli S. dan Hamada T. Menuju Gigi dan Mulut Sehat, Pencegahan dan Pemeliharaan. USU Press. Medan. 2008

20. Bakar A. Kedokteran Gigi Klinis, Ed 2. Yogyakarta. CV Quantum Sinergis Media. 2014;51-135

21. Taringan R. Karies Gigi, ed 2. EGC. Jakarta. 2012;15-22

22. Shasank SG., dkk. Dental Caries and its Relationship to Malocclusion in Permanent 
Dentition among 12-15 Year Old School Going Children. Journal of International Oral Health. 2014;6(5): 27-30

23. Carlos AF., dkk. Impact of Malocclusion and Dentofacial Anomalies on the Prevalence and Severity of Dental Caries among Adolescents. January 2015. Angle Orthodontist. Vol 00. No. 0,0000

24. Widyastuti, dkk. Kesehatan Reproduksi. Yogyakarta. Fitramaya. 2009;10-20

25. Harty FJ., dan Ogston R. Kamus Kedokteran Gigi, Jakarta. EGC. 1993;189

26. Hassan R. dan Rahimah A. Occlusion, Malocclusion and Method of Measurement An Overview. J Orofacial Sci. 2007;2: 3-9.

27. Thomson H. Oklusi, Ed 2. Jakarta. EGC. 2007

28. Suminy D dan Zen Y. Hubungan antara maloklusi dan hambatan saluran pernapasan Kedokteran Gigi Scientific Journal in Dentistry; FKG Trisakti; 2007; 22(1): 32-3.

29. Need dan demand serta akibat dari maloklusi pada siswa SMU Negeri 1 Binjai. 2011 [internet] Available from: http://repository.usu.ac.id/bitstream/123456789 /18207/4/Chapter\%20II.pdf.
30. Rahardjo P. Diagnosis Ortodontik. Surabaya: Airlangga University Press. 2011;

31. Putri MH., dkk. Ilmu Pencegahan Penyakit Jaringan Keras dan Jaringan Pendukung Gigi. EGC. 2009;154-161

32. Koernati I. Perkembangan Perawatan Gigi Masa Depan. Andalas University Press. 2006;116-135

33. Irma IZ. dan Ayu SI. Penyakit Gigi, Mulut dan THT. Yogyakarta. Nuha Medika. 2013;18-26

34. Hongini SY. dan Aditiawarman M. Kesehatan Gigi dan Mulut. Pustaka Reka Cipta. 2012;3751

35. Saryono. Metodologi Penelitian Kesehatan. Yogyakarta. Mitra Medika Press. 2011;67

36.Cypriano S., dkk. Evaluation of Simplified DMF-T Indices in Epidemiological Survey of Dental Caries. Rev Saude Publica. 2005;39(2)

37.Cahyadi NS. Faktor-Faktor yang Berhubungan dengan Status Karies Gigi Anak Sekolah Dasar Kelas 6 di Kecamatan Tanjung Priok Jakarta Utara Tahun 1997. Tesis. Fakultas Kesehatan Masyarakat Universitas Indonesia 